\title{
Drug Utilization Pattern of Antihypertensive Drugs at Tertiary Care Teaching Hospital
}

Dr. Mirza Arshad Asif Baig ${ }^{1}$, Dr. Naveed Altaf ${ }^{2^{*}}$

${ }^{1}$ Assistant Professor, Dr. VRK Women's Medical College Teaching Hospital \& Research Center, Aziznagar, Moinabad

${ }^{2}$ Assistant Professor, Shadan Institute of Medical Sciences Teaching Hospital \& Research Center, Hyderabad

\section{Article History \\ Received: 12.01 .2021 \\ Accepted: 18.03 .2021 \\ Published: 27.03.2021 \\ Journal homepage: \\ https://www.easpublisher.com}

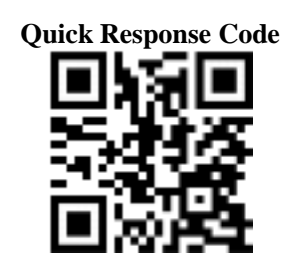

\begin{abstract}
Background: Hypertension is a global public health issue. It is a significant contributor to rising morbidity and mortality because of its associations with cardiovascular, renal and cerebrovascular complications. A drug utilization review on antihypertensive drugs should be done to determine different classes of antihypertensive medications with respect to diagnosis. Aim was to study drug utilization pattern of antihypertensive medication in a tertiary care teaching hospital. Methods: This is a prospective, observational and descriptive study conducted between September 2020 to February 2021 at outpatient Department of General Medicine, Dr. VRK Women's Medical College Teaching Hospital \& Research Center. Prescriptions of 130 patients of either sex and age $>18$ years who have been diagnosed with hypertension as per JNC-8 guidelines and patients receiving or prescribed with antihypertensive medications were included. Results: The highest age group patients were between 51-60 years accountable $27.4 \%$ and least age group patients were between $18-30$ years $8.1 \%$. The gender ratio of the patients' male: female was found to be $1.2: 1$. Out of the 135 patients, $64.4 \%$ (83) of patients were male and $38.5 \%$ (52) of patients were female. Test of proportion showed that the male patients were slightly more than the female patients. Most of the patients $53(39.2 \%)$ were significantly higher systolic blood pressure ranging between 160-179 $\mathrm{mmHg}$ (Stage 2 HTN) and least patients were emergency hypertensive were $5.1 \%$. Most of the patients 73 $(54.0 \%)$ were on Mono therapy significantly higher than dual therapy, triple therapy and poly therapy, $36(26.6 \%), 17(12.5 \%), 9(6.6 \%)$ respectively. Calcium channel blocker was the frequently used class of drug for monotherapy $(17.0 \%)$. In dual drug therapies were $\mathrm{CCB}+\mathrm{ARB}$ accounting for $13.3 \%$, and $8.1 \%$ of patients were on triple drug therapy with $\mathrm{CCB}+\mathrm{ARB}+$ Diuretic. Causality assessment of ADRs was done using WHO-UMC scale shows that type of reactions and their percentage are as certain (19.3\%), Probable/ Likely $(67.7 \%)$, Possible $(9.6 \%)$ and Unlikely (3.2 \%). Conclusion: Large differences in utilization of different groups of antihypertensive agents were noted in this study. This type of studies gives the base line idea of prescription pattern and ADRs of antihypertensive drugs. These helps to design policy for rational use of drugs and motivation of physician for rational use of drugs.

Keywords: Antihypertensive, Drug utilization, Adverse drug reaction.
\end{abstract}

Copyright ( 12021 The Author(s): This is an open-access article distributed under the terms of the Creative Commons Attribution 4.0 International License (CC BY-NC 4.0) which permits unrestricted use, distribution, and reproduction in any medium for non-commercial use provided the original author and source are credited.

\section{INTRODUCTION}

Hypertension is a highly prevalent chronic health condition with its devastating consequences on the heart and cardiovascular system. Blood pressure varies from person to person, and from time to time for individuals, however, if the blood pressure is constantly elevated above $140 / 90 \mathrm{mmHg}$ at different times of measurement, it is regarded as high blood pressure (hypertension) [2]. In the year 2000 hypertension was estimated to affect almost one billion patients worldwide. Prevalence is predicted to increase by approximately $60 \%$ by 2025 [3].
A number of national and international guidelines for the treatment of hypertension have been published. The most recent JNC 8 guideline recommends diuretics as the first-line treatment in hypertension [4, 5]. Due to high prevalence of hypertension and the requirement of medications for prolonged periods, the drug treatment cost poses a major issue in health economics. In developed countries, the expenditure on antihypertensive therapy has increased sharply in recent years due to increasing use of newer and more expensive drugs such as calcium-channel blocking agents, angiotensinconverting enzyme inhibitors and angiotensin-receptor antagonists [6]. 
Changes over time in terms of recommended guidelines and innovations in drug formulations have resulted in modifications to the prescription patterns of antihypertensive drugs. Availability of numerous antihypertensive gives physicians several options to individualize the therapy [7]. Due to this fact there is change in the prescribing pattern from patient to patient and physician to physician. The reason for this variation in the prescribing pattern is due to the conflict of interest of physicians [8].

The World Health Organization (WHO) defines drug utilization research as "the marketing, distribution, prescription and use of drugs in a society, with special emphasis on the resulting medical, social, and economic consequences" [9]. Thus, inherent in the definition, such studies provide logical background for determining the rationality of drug use as well as providing evidence based guidance for making policy decisions at various levels of healthcare [10]. Drug utilization research studies conducted in the inpatient settings are effective tools that help in evaluating the drug prescribing trends, efficiency, and costeffectiveness of hospital formularies. There is always a variation in drug utilization among different countries and even among health institutions within a country and sometimes within the same institute at different point of time probably because of changing disease trends over a period of time [11].

\section{Materials ANd Methods}

This is a prospective, observational and descriptive study conducted between September 2020 to February 2021 at outpatient Department of General Medicine, Dr.VRK Women's Medical College Teaching Hospital \& Research Center. Prescriptions of 130 patients of either sex and age $>18$ years who have been diagnosed with hypertension as per JNC-8 guidelines and patients receiving or prescribed with antihypertensive medications were included. Patients in emergency, life threatening medical or surgical conditions, pregnant and lactating women and patients with incomplete data were excluded. The patient's sociodemographic profile, receiving or current prescribing patterns of antihypertensive medications were recorded in a predesigned data collection record form. Those receiving or with prescription of a one active principle medication was considered as monotherapy and those receiving or prescription of a more than one active principle medications were defined as a polytherapy.

The main aim of study was evaluating the different classes of antihypertensive medications with respect to diagnosis and to carry out the drug utilization review in hypertension with its different combinations. Patient's demographics, type of antihypertensive drug prescribed, lab reports, detailed medical history, concomitant medications for co morbid diseases were recorded. Frequency of drug prescription among different age groups, frequency of administration of individual drugs, frequency of prescribing combination drugs, frequency of prescribing fixed drug combinations, number of prescriptions per drug, number of drugs prescribed per total number of prescription, percentage of patients in the treatment of hypertension with comorbidities, percentage of economic difference, percentage of expenditure cost, and average drug acquisition cost (ADAC) were calculated.

\section{Adverse Drug Reactions}

In the present study, causality assessment between the drug and suspected reaction was determined by using WHO-UMC Scale, Naranjo Scale and Hartwig and Siegel scale. According to Naranjo Criteria, the ADRs are analysed on the basis of a questionnaire comprising 10 questions in which each question is given a score of $+2,+1,0$ or -1 depending on the analysis. When total if the score is $>9-$ labelled as definite ADR, if 5-8 - probable ADR, if 1-4 possible ADR, if 0 - doubtful ADR.

\section{Statistical Analysis}

Data was analysed using the software, Statistical Package for Social Sciences (SPSS for windows. Version 25 software. Percentage describes categorical data mean \pm standard deviation (SD) describes continuous data Subjects were recruited in the study. All drug related adverse events were evaluated according to the "WHO causality Assessment Scale" was used to describes causality of adverse drug event into adverse drug reaction.

\section{RESULTS}

\section{Age distribution of patient}

In table 1, the highest age group patients were between 51-60 years accountable 27.4\% and least age group patients were between $18-30$ years $8.1 \%$.

Table-1: Distribution of age group

\begin{tabular}{|l|l|l|}
\hline $\begin{array}{l}\text { Age group in } \\
\text { years }\end{array}$ & $\begin{array}{l}\text { No. of patients } \\
(\mathbf{n = 1 3 5})\end{array}$ & Percent \\
\hline $18-30$ & 11 & 8.1 \\
\hline $31-40$ & 31 & 22.9 \\
\hline $41-50$ & 33 & 24.4 \\
\hline $51-60$ & 37 & 27.4 \\
\hline$>61$ & 23 & 17.0 \\
\hline
\end{tabular}

Table-2: Distribution of gender

\begin{tabular}{|l|l|l|}
\hline Gender & No. of patients & Percent \\
\hline Male & 83 & 61.4 \\
\hline Female & 52 & 38.5 \\
\hline
\end{tabular}




\section{Gender distribution of patient}

In table 2, the gender ratio of the patients' male: female was found to be $1.2: 1$. Out of the 135 patients, $83(61.4 \%)$ of patients were male and 52 $(38.5 \%)$ of patients were female. Test of proportion showed that the male patients were slightly more than the female patients.

Table-3: Duration of hypertension

\begin{tabular}{|l|l|l|}
\hline Duration in years & No. of patients & Percent \\
\hline$<3$ years & 69 & 51.1 \\
\hline 4-6 years & 41 & 30.3 \\
\hline$>7$ years & 25 & 18.5 \\
\hline
\end{tabular}

\section{Duration of hypertension}

In table 3 shows that $69(51.1 \%)$ patients were between $<3$ years, $41(30.3 \%)$ patients were between 4 6 years and $25(18.5 \%)$ were having history of $>7$ years.

Table-4: Distribution of Systolic blood pressure

\begin{tabular}{|l|l|l|}
\hline $\begin{array}{l}\text { Systolic blood pressure } \\
\text { (mmHg) }\end{array}$ & $\begin{array}{l}\text { No. of } \\
\text { patients }\end{array}$ & Percent \\
\hline $120-139$ (Pre HTN) & 34 & 25.1 \\
\hline $140-159$ (Stage 1 HTN) & 41 & 30.3 \\
\hline $160-179$ (Stage 2 HTN) & 53 & 39.2 \\
\hline$>180$ (HTN emergency) & 7 & 5.1 \\
\hline
\end{tabular}

\section{Systolic blood pressure distribution in patients}

In table 4 depicts most of the patients 53 $(39.2 \%)$ were significantly higher systolic blood pressure ranging between 160-179 $\mathrm{mmHg}$ (Stage 2 HTN) and least patients were emergency hypertensive were $5.1 \%$.

Table-5: Distribution of Diastolic blood pressure

\begin{tabular}{|l|l|l|}
\hline $\begin{array}{l}\text { Diastolic blood pressure } \\
\text { (mmHg) }\end{array}$ & $\begin{array}{l}\text { No. of } \\
\text { patients }\end{array}$ & Percent \\
\hline $80-89$ (Pre HTN) & 31 & 22.9 \\
\hline $90-99$ (Stage 1 HTN) & 37 & 27.4 \\
\hline $100-119$ (Stage 2 HTN) & 59 & 43.7 \\
\hline$>120$ (HTN emergency) & 8 & 5.9 \\
\hline
\end{tabular}

Diastolic blood pressure distribution of patients

In table 5, test of proportion showed most of the patients $59(43.7 \%)$ were significantly higher diastolic blood pressure ranging between 100-119 $\mathrm{mmHg}$ and least patients were emergency hypertensive were $5.9 \%$.

Table-6: Distribution of drug therapy

\begin{tabular}{|l|l|l|}
\hline Drug Therapy & No. of patients & Percent \\
\hline Monotherapy & 73 & 54.0 \\
\hline Dual therapy & 36 & 26.6 \\
\hline Triple therapy & 17 & 12.5 \\
\hline Poly therapy & 9 & 6.6 \\
\hline
\end{tabular}

\section{Drug therapy distribution among patients}

In table 6 shows most of the patients 73 (54.0\%) were on Mono therapy significantly higher than dual therapy, triple therapy and poly therapy, 36 (26.6\%), 17 (12.5\%), 9 (6.6\%) respectively.

Table-7: Utilization pattern of different antihypertensive drugs

\begin{tabular}{|l|l|l|}
\hline Treatment & $\begin{array}{l}\text { No. of patients use } \\
\text { antihypertensive } \\
\text { drug }\end{array}$ & Percent \\
\hline Monotherapy & 17.0 \\
\hline $\begin{array}{l}\text { Calcium channel } \\
\text { blocker }\end{array}$ & 23 & 12.5 \\
\hline ARB & 17 & 6.6 \\
\hline ACE Inhibitor & 9 & 14.0 \\
\hline Beta Blocker & 19 & 1.4 \\
\hline Alpha Blocker & 2 & 2.2 \\
\hline Diuretics & 3 & 13.3 \\
\hline Dual therapy & 18 & 8.1 \\
\hline CCB+ARB & 11 & 3.7 \\
\hline CCB+Beta Blocker & 5 & 1.4 \\
\hline CCB+Diuretic & 2 & 8.1 \\
\hline ARB+ Diuretic & \multicolumn{2}{|l}{} \\
\hline Triple therapy & 11 & 4.4 \\
\hline CCB+ARB+Diuretic & 11 & \\
\hline $\begin{array}{l}\text { CCB+B } \\
\text { Blocker+Diuretic }\end{array}$ & 6 & \\
\hline
\end{tabular}

Utilization pattern of different antihypertensive drugs

In table 7, Calcium channel blocker was the frequently used class of drug for monotherapy $(17.0 \%)$. In dual drug therapies were $\mathrm{CCB}+\mathrm{ARB}$ accounting for $13.3 \%$, and $8.1 \%$ of patients were on triple drug therapy with $\mathrm{CCB}+\mathrm{ARB}+$ Diuretic.

Table-8: WHO causality assessment of ADRs

\begin{tabular}{|l|l|l|}
\hline Type of reaction & $\begin{array}{l}\text { No. of patients } \\
\text { reported ADR } \\
(\mathbf{3 1})\end{array}$ & Percent \\
\hline Certain & 6 & 19.3 \\
\hline Probable/likely & 21 & 67.7 \\
\hline Possible & 3 & 9.6 \\
\hline Unlikely & 1 & 3.2 \\
\hline Conditional/unclassified & - & - \\
\hline $\begin{array}{l}\text { Unassessable/ } \\
\text { unclassifiable }\end{array}$ & - & - \\
\hline
\end{tabular}

In table 8 , among 135 patients only 31 patients experienced ADRs. Causality assessment of ADRs was done using WHO-UMC scale which categorizes ADRs as "certain", "probable", "possible" and "unlikely". Table 8 shows that type of reactions and their percentage are as certain (19.3\%), Probable/ Likely $(67.7 \%)$, Possible (9.6\%) and Unlikely (3.2\%). 
Table-9: Severity of reported ADRs by modified Hartwig and Siegel scale

\begin{tabular}{|l|l|l|}
\hline Type of reaction & No. of patients reported ADR (43) & Percent \\
\hline Lethal & - & - \\
\hline Severe & 1 & 3.2 \\
\hline Moderate & 7 & 22.5 \\
\hline Mild & 23 & 74.1 \\
\hline
\end{tabular}

In table 9, it was found that from all ADRs, reported (74.1\%) were mild, $(22.5 \%)$ moderate and only $(3.2 \%)$ was classified as severe.

Table-10: Common ADR Reported

\begin{tabular}{|l|l|l|l|}
\hline Class of drugs & Adverse events experienced & No of patients (31) & \% \\
\hline CCB & Pedal edema, giddiness, headache, abdominal pain, bradycardia & 8 & 25.8 \\
\hline ARB & $\begin{array}{l}\text { Anxiety, Nausea and Vomiting, Headache, Abdominal pain, } \\
\text { Restlessness, Itching and inflammatory swelling }\end{array}$ & 6 & 19.3 \\
\hline ACE Inhibitor & $\begin{array}{l}\text { Dry cough, dizziness, headache, drowsiness, diarrhea, } \\
\text { hypotension, weakness, cough, rash, metallic or salty taste. }\end{array}$ & 11 & 35.4 \\
\hline Beta Blocker & $\begin{array}{l}\text { Constipation, nausea and vomiting, headache, hypoglycemia, } \\
\text { postural hypotension }\end{array}$ & 3 & 9.6 \\
\hline Diuretics & $\begin{array}{l}\text { Hypotension, muscle cramps, headache vertigo, pain in legs, } \\
\text { dysuria }\end{array}$ & 2 & 6.4 \\
\hline Other & Skin reaction & 1 & 3.2 \\
\hline
\end{tabular}

Total 31 patients were reported ADR. $35.4 \%$ patients were on ACE inhibitors. $25.8 \%$ patients receiving Calcium channel blocker reported side effect.

\section{DISCUSSION}

The WHO defines drug utilization studies as "the marketing, distribution, prescription and the use of drugs in a society, with special emphasis on the resulting medical, social and economic consequences." Prescription pattern surveys are an important methodological instrument of drug utilization studies, which help provide an in-depth insight into the disease profile of patients and prescribing behaviour of clinicians. Hypertension is a serious public health problem worldwide [12]. It is the leading cause of death in the world and is the most common cause for outpatient visits to physicians [13].

In this study, the maximum number of patients, were from the age group of 51-60 (27.4\%) years followed by $41-50(24.4 \%)$ and least number in $18-30(8.1 \%)$ years of age of patients are from this age group. Whereas, total 135 patients were there, including $83(61.4 \%)$ males and $52(38.5 \%)$ females (Table 2$)$ and showing a predominance of male population. The hypothetical cause of higher number of male patients is elevated levels of androgen such as testosterone as they play a role in elevation of blood pressure [14]. A similar study was also conducted by Paradkar SG, et al, which is supporting this study [15].

The present study observed that single-drug therapy $(54.0 \%)$ as a CCBs was more commonly employed than multiple-drug therapy. These results support the work of Adake P et al. which showed blood pressure could be adequately controlled with the help of single-drug therapy [16]. This might be attributed to patient's compliance, good response, and less incidence of adverse effects. In a study by Kale A et al, CCBs were found to be the most frequently used group of drugs which is parallel to findings of our study [17]. In our study, BBs were prescribed most frequently next to CCBs the findings of which are similar to the study performed in a tertiary care hospital of India by Shah $\mathbf{J}$ PR et al [18].

In this present study, it was observed that there was a significant change in antihypertensive prescribing pattern with a considerable increase in the frequency of intake of CCBs, ARBs, ACEIs and BBs. These observations line with other study [19]. CCBs and ARBs constitute the most frequently prescribed antihypertensive drug class. Increased prescription of ARBs and CCBs probably suggest that clinicians are more aware of the long term cardiovascular and renovascular benefits. The prescriptions were also in accordance with the evidence and the guidelines, as these medications will reduce the chance of occurrence of diabetic nephropathy, retinopathy and other related complications in diabetes patients. When calcium channel blockers were concerned the most commonly prescribed drugs were the dihydropyridine type of calcium channel blockers (ie., Amlodipine), whereas the prescription of non-dihydropyridine type of calcium channel blockers was very less.

Observations on combination therapy reflect that the most commonly prescribed drugs in combination were diuretics (i.e., Thiazide and 
potassium sparing diuretic groups). The joint national committee on prevention, detection, evaluation and treatment of High blood pressure (JNC-8) report notes that volume overload due to inadequate diuretic therapy is one of the commonest reason for resistance observed in HTN treatments [20]. So, there is a paradigm shift towards increased prescribing of combination therapy. The present observational study depicts that the patients with co-morbidity were prescribed one or two antihypertensive along with other medications to treat their associated diseases such as diabetes mellitus, IHD, CVA and Bronchial asthma. In a study by Hussain IM et al, the most commonly prescribed antihypertensive among elderly patients was Amlodipine [21]. This is also in consonance with the recommendations of the JNC on Prevention, Detection, Evaluation, and Treatment of high blood pressure guidelines which state that low dose of different classes of antihypertensive drugs is more beneficial than a high dose of one [22].

According to WHO-UMC Scale maximum number of ADRs in probable class followed by possible, unlikely and certain class. Moreover, as per the modified Hartwig and Siegel's scale maximum number of ADRs was mild category and lowest in sever type of reaction was observed in this study. No ADRs were found in lethal type of reaction. These findings were consistent with the literature reported by Rachana PR et al, Total 31 patients were reported ADR [23]. In our study, $35.4 \%$ patients were on ACE inhibitors. 25.8 $\%$ patients receiving Calcium channel blocker reported side effect.

Finally, the strength of this study lies firstly in the unparalleled period of consideration ( 8 months). Earlier studies have been characterized by a relatively short period of consideration (usually not exceeding 3 months) with a tangible majority of them having comparatively smaller sample sizes [24]. It is noteworthy also that there is no prior study of this kind in a secondary healthcare setting. Furthermore, the result of this study represents a much more recent (and arguably more reliable) assessment of the subject matter and, as such, is hoped to not only merit publication but also attract attention as a renewed, data-driven basis for further research in the management and control of hypertension, ultimately.

\section{CONCLUSION}

In conclusion, our study analysed the drug utilization of antihypertensive medication and found that the prescribing pattern was totally consistent with the JNC 8 (the Eighth Report of the JNC on Prevention, Detection, Evaluation, and Treatment of High Blood Pressure) guidelines for the treatment of hypertension. Monotherapy was consistently more recommended in the early stages of hypertension to achieve target goal of blood pressure, and CCBs were the drugs of choice for hypertensive patients.
The knowledge and prescription of drug was concluding to be the base line idea of ADRs of antihypertensive drugs in hypertensive patients visiting OPD of tertiary teaching care hospital in India. In this study, we can say that all of the prescriptions found were rational; furthermore, more changes are needed to be done in prescription of antihypertensive drugs are needed in drug prescribing practices in hypertensive patients. Patients are needed to provide information and proper counselling regarding the ADRs of drugs; this would refine the quality of life.

\section{REFERENCES}

1. Nachiya JRA, Parimalakrishnan S, Rao RM. (2015). Study on drug utilization pattern of antihypertensive medications on out-patients and inpatients in a tertiary care teaching hospital: A cross sectional Study. Afr J Pha Pharmacol. 22;9(11):383-96.

2. Gupta R, Gaur K and Ram CVS. (2019). Emerging trends in hypertension epidemiology in India. $J$ Hum Hypertens. 33(8): 575-87.

3. Singh D, Katiyar P, Sawlani KK, Chaudhary SC, Nath R, Fatima SS, Kumar A and Dixit RK. (2020). Drug utilization study of antihypertensive treatment being prescribed in patients coming to medicine OPD of a tertiary care hospital in northern India. Int J Pharm Sci \& Res. 11(3): 141016.

4. James PA, Oparil S, Carter BL, Cushman WC, Himmelfarb CD, Handler J, et al. (2014). Evidence-based guideline for the management of high blood pressure in adults. Report from the panel members appointed to the eighth joint national committee (JNC 8). JAMA. 311(5):50720.

5. Sluss PM (2017) Utilization Management Initiatives That Can Be Imported into Healthcare Systems. Utilization Management in the Clinical Laboratory and Other Ancillary Services: Springer pp. 287-290.

6. Lim SS, Vos T, Flaxman AD, Danaei G, Shibuya K, Adair-2. Rohani H, et al. (2012). A comparative risk assessment of burden of disese and injury attributable to 67 risk factors and risk factor clusters in 21 regions, 1990-2010: a systematic analysis for the Global Burden of Disease Study 2010. Lancet. 380: 2224-60.

7. Owolabi, M, Olowoyo, P, Miranda, JJ, et al. (2016). Gaps in hypertension guidelines in lowand middle-income versus high-income countries: a systematic review. Hypertension. 68:1328-1337.

8. Datta S. (2016). Utilization study of antihypertensives in a South Indian tertiary care teaching hospital and adherence to standard treatment guidelines. J Bas Clin Pharma. 8(1):33

9. Ramadas S, Sujatha MB, Andrews MA and B SK. (2019). Drug utilization study of antihypertensive drugs and prevalence of blood pressure control in 
adult hypertensive patients based on JNC VIII guidelines in a tertiary care hospital: a cross sectional study. Int J Basic Clin Pharmacol. 8(2): 245-52.

10. Shin, HY, Kang, HT. (2018). Recent trends in blood pressure according to economic status: Korean National Health and Nutrition Examination Survey from 2005 to 2015. Asia Pac J Public Health. 30:266-275.

11. Vummareddy H, Mudhaliar MR, Ishrar SM, Sandyapakula B, Vobbineni L and Thomas B. (2017) Prescribing pattern and cost analysis of antihypertensives in India - CHRISMED. $J$ Health Res. 4(2): 94-98.

12. Raikar SR, Patil SB, Raikar DR and Mantale N. (2017). Drug utilization study of antihypertensive drugs in hypertensive diabetic patients in a tertiary care hospital. Int J Basic Clin Pharmacol. 4(4): 739-43.

13. Vashishta K. (2018). Study on drug utilization pattern of antihypertensive medication in tertiary care hospital of Telangana, India. Int J Basic Clin Pharmacol. 7:1770-4.

14. Mankadavath, A, Chandrasekhar, D, Thomas, T, Zuhra, F, Kaipanthodi, S, Parambil, JC. (2015). A prospective drug use evaluation of antihypertensive drugs in in-patients of a tertiary referral care hospital. J Basic Clin Physiol Pharmacol. 26:295300.

15. Paradkar SG, Sinha, SR. (2018). Drug utilization among hypertensive patients in the outpatient department of medicine in a tertiary care hospital: a cross-sectional study. Clin Exp Hypertens. 40:150154.

16. Adake P, Bhat, NP, Nayak, RP, Hafis, T, Bhagyashree, A, Raj, PV. (2017). Study on prescribing pattern of antihypertensive drugs in a tertiary care hospital. Adv Pharmacol Pharm. 5:2124.

17. Kale A, Maniyar YA, Kale A. (2013). Prescribing Patterns of Antihypertensive Drugs in A Tertiary Care Hospital. SchAcad J Pharm, 2(5): 416-418.

18. Shah J, Khakhkhar T, Bhirud S, et al., (2013). Study of utilization pattern of anti-hypertensive drugs in hypertensive diabetic patients with or without reduced renal function at tertiary care teaching hospital. IJMSPH 2(2): 170-180.

19. Behanan A, Ammu A, Supriya A, Devaasy A and Kumar A. (2016). Drug utilization study of antihypertensive medications in a tertiary care teaching hospital in Tamil Nadu. World J Pharm Sci. 5(10): 1534-40.

20. Meena DK and Jayanthi M. (2019). Drug utilization research: a review. Int J Basic Clin Pharmacol. 8(2): 354-61.

21. Hussain IM, Naqvi, BS, Qasim, RM, Ali, N. (2015). Current trends in treatment of hypertension in Karachi and cost minimization possibilities. Pak J Med Sci. 31:1021-1026.

22. Jain S, Upadhyaya P, Goyal J, Kumar A, Jain P and Seth V. (2015). A systematic review of prescription pattern monitoring studies and their effectiveness in promoting rational use of medicines. Perspect Clin Res. 6(2): 86-90.

23. Rachana PR, Anuradha HV, Shivamurthy M. (2014). Antihypertensive prescribing patterns and cost analysis for primary hypertension: A retrospective study. J Clin Diagn Res. 8:19-22.

24. Reddy, P, Kumar, R, Swathi, D. (2018). Current trend in prescribing pattern of antihypertensive drugs in a tertiary care teaching hospital: a prospective observational study. Indo Am J Pharm Sci. 5:1603-1610.

Cite This Article: Mirza Arshad Asif Baig \& Naveed Altaf (2021). Drug Utilization Pattern of Antihypertensive Drugs at Tertiary Care Teaching Hospital. EAS J Pharm Pharmacol, 3(2), 45-50. 